\title{
Evaluation of the Effects of Core-Quick Strength and Core-Plyometric Studies on Balance, Agility and Strength Traits of Volleyball Players
}

\section{Uğur DEVRİM ${ }^{1}$ Kâmil ERDEM ${ }^{\star \rtimes}$ (iD}

Marmara University, Faculty of Sports Sciences, İstanbul, Turkey.

'Email:ugur_devrimm@hotmail.com.Tel.90+053342937065

${ }^{2}$ Email: kerdem@marmara.edu.tr Tel: 90+05327336604

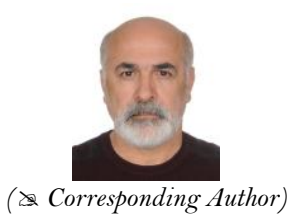

\begin{abstract}
The aim of this study is to investigate the effects and differences of two different strength training models on balance, agility and strength traits of volleyball players. 45 female athletes aged 12.08 \pm 0.82 who played volleyball in a private club participated in the study. The athletes who participated in the study were divided into three groups as core-plyometric (KRP) $(n=15)$, corequick strength $(\mathrm{KRC})(\mathrm{n}=15)$ and control $(\mathrm{KNL})(\mathrm{n}=15)$ groups. Within the scope of the study, KRP group performed plyometric training after core training and KRC group performed quick strength training after core training. The KNL group continued their volleyball training The trainings were conducted 2 days a week for 8 weeks. Height, weight, BMI, t-test, standing long jump test, flamingo balance test and throw-in test were applied to all three groups before and after the study. The data obtained in the pre and post test were evaluated with a statistics package program and the significance level was determined as $\mathrm{p}<0.05$. The One-Way ANOVA test and Paired-Samples t-test were used for statistical analysis. As a result, a significant difference was found in the standing long jump test in all three groups $(\mathrm{p}<0.05)$. Throw-in and flamingo balance tests showed a significant difference in the KRP and KRC groups $(\mathrm{p}<0,01)$, but not in the KNL group $(p>0,05)$. T-test showed significant difference in KRP and KRC groups $(p<0.05)$, but no significant difference was found in KNL group $(p>0,05)$. When the differences between the groups were examined,no significant differences were found between the averages as a result of height, standing long jump, throw-in and flamingo balance tests ( $p>0.05)$, and the KRC group showed significantly more improvement than the KNL group in the t-test.
\end{abstract}

Keywords: Plyometric, Balance, Agility, Core, Strength, Volleyball.

Citation | Uğur DEVRIM; Kâmil ERDEM (2019). Evaluation of the Effects of Core-Quick Strength and Core-Plyometric Studies on Balance, Agility and Strength Traits of Volleyball Players. Asian Journal of Education and Training, 5(3): 482-487. History:

Received: 26 June 2019

Revised: 1 August 2019

Accepted: 9 September 2019

Published: 11 October 2019

Licensed: This work is licensed under a Creative Commons

Attribution 3.0 License $($ (c) EY

Publisher: Asian Online Journal Publishing Group
Acknowledgement: Both authors contributed to the conception and design of the study.

Funding: This study received no specific financial support.

Competing Interests: The authors declare that they have no conflict of interests.

Transparency: The authors confirm that the manuscript is an honest, accurate, and transparent account of the study was reported; that no vital features of the study have been omitted; and that any discrepancies from the study as planned have been explained.

Ethical: This study follows all ethical practices during writing.

\section{Contents}

1. Introduction

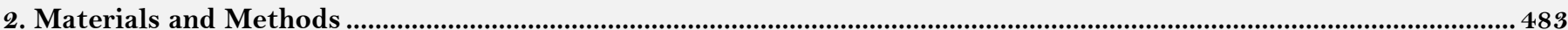

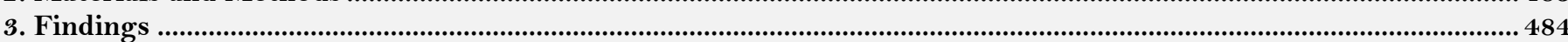

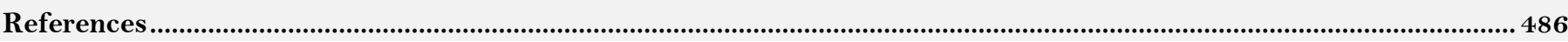




\section{Contribution of this paper to the literature}

This study contributes to the existing literature by investigating the effects and differences of two different strength training models on balance, agility and strength traits of volleyball players.

\section{Introduction}

Volleyball involves movements consisted of technical and tactical skills of different intensity performed in an aerobic environment in terms of playing time (Gabbett et al., 2007; Busko et al., 2013). Biomotor traits such as high aerobic and anaerobic endurance, strength, flexibility, speed, agility, balance, reaction are also effective in game performance (González et al., 2011; Bazyler et al., 2018; Sopa and Pomohaci, 2018).

Sudden changes in direction, jumping in different positions and agility trait involving speed changes affect performance in volleyball (Sheppard et al., 2008). Agility is body control and the ability to change direction suddenly (Barnes et al., 2007). In another definition, it is described as a locomotor skill that enables the body to change its direction as fast, smooth, easy and controlled as possible while moving between two points (Turner, 2011). The static and dynamic balance adequacy of core area muscle groups which provide connection between body, legs and arms also affects agility (Makhlouf et al., 2018). In addition, the strength development of the core area has a positive effect on the balance system of the body and provides support to the movement economy and positively affects the power output (Herrington and Davies, 2005; Carpes et al., 2008; Mcgill, 2010).

The balance feature, which is one of the important parameters of physical movements (Hrysomallis, 2011) is known to play an important role in successful exhibition of many sports skills, in changing direction, stopping, moving an object, maintaining certain position of the body and preventing injury (Oliver and Di Brezzo, 2009; Shubert et al., 2010). In almost all sports branches, the most successful athletes have superior control over the center of gravity and therefore their balance traits are at the highest level (Roetert, 2001).

In order to develop the explosive force which is another effective physical feature in volleyball, the force and speed relationship should be at the highest level. In this context, plyometric training is one of the most used methods (Haghighi et al., 2012). Plyometric study is a kind of neuromuscular studpaly that leads to the development of explosive force to use maximum force at minimum time (Nikseresht et al., 2014). In-game jumping skills should be developed sufficiently for players to practice spike and block techniques well. In a study they conducted, Reeser and Bahr (2017) reported that volleyball players jump between 30,000 and 40,000 times in a year. Therefore, it is necessary to pay attention to the parameters that affect the ability to jump in all kinds of training practices aimed at increasing the sporting performance of volleyball players.

Another training method which can be implemented on the ability to jump in volleyball is the quick strength training. The quick strength training is an important type of training used in the development of agility, strength and jump (Rodríguez et al., 2017). The movements used in volleyball should be quick and the techniques should be proper. Therefore, the training practices that combine strength trainings with speed should be consistent with the volleyball technique (Bompa and Carrera, 2003). Within the framework of this approach, the aim of this study is to investigate the effects and differences of two different strength training models on balance, agility and strength traits of volleyball players.

\section{Materials and Methods}

45 licensed female athletes playing volleyball were included in this study. At the beginning of the training sessions, the athletes were homogeneously distributed to 3 groups according to the pre-test results by using the pairing method. There was no significant difference between the averages of the groups and the One-Way Anova test results. The athletes were divided into 3 groups as core-plyometric $(\mathrm{KRP})(\mathrm{n}=15$, age: 12,0 $\pm 0,83$ years, weight: $55,6 \pm 6,2 \mathrm{~kg}$, height: $168,7 \pm 4,33)$, core-quick force $(\mathrm{KRC})(\mathrm{n}=15$, age: $12,1 \pm 0,79$ years, weight: 40,7 $\pm 3,74 \mathrm{~kg}$, height: $165,7 \pm 4,39 \mathrm{~cm})$ and control group $(\mathrm{KNL})(\mathrm{n}=15$, age: 12,2 $\pm 0,86$ years, weight: 56,5 $\pm 8,03 \mathrm{~kg}$, height: $167,9 \pm 7,63 \mathrm{~cm})$. The KRP group participated in plyometric training after core training and the KRC group participated in quick strength training. The KNL group continued traditional volleyball training. A total of 16 sessions were conducted for 8 weeks, 2 days a week. In the training days, the sessions consisted of 4 phases. These were; the warm-up phase, core-plyometric and core-quick force training practices, volleyball-specific technicaltactical training of the coach and finishing phase. In order to avoid differences in the study, predefined standard warm-up drills were implemented in all three groups.

Preliminary and final tests were performed in the study. Height and weight measurements were taken as the anthropometric measurements, throw-ins and standing long jumps were used as the strength test the flamingo balance test and t-test were also implemented. Care was taken to ensure that the coaches performing the tests were the same during both test periods. The participants were asked to rest completely before testing.

Height and Body Weight: Length measurements were taken with a wall-mounted wall scale. All heights were taken while the heels were in contact with the platform perpendicular to the hip and scapula and the subjects were in an upright position (Weiner and Lourie, 1969). Body weight measurements were taken using a digital display scale with a sensitivity of $0.01 \mathrm{~kg}$. During the measurements, the heavy equipment of the subjects other than the shorts and t-shirts were removed (Weiner and Lourie, 1969).

Body mass index (BMI): The ratio of body weight to height was calculated by using this formula: weight $(\mathrm{kg})$ /height $(\mathrm{m}) 2$.

Agility measurements: T-test was used (Semenick, 1990). 4 cones, tape measure and photocell were used. The athletes were asked to run a total distance of 36.57 meters in as short a time as possible. The time was recorded in seconds.

Balance measurements: The flamingo static balance test was applied (Sipal, 1989). The aim is to determine how many seconds the static balance of the subject is within one minute. The shortest execution time was discarded and the best of the two execution times was taken and recorded as the test score.

Strength tests: Throw-in and standing long jump tests were implemented. 
Throw-in test: Measures the circumference of the shoulder-chest muscles and the strength of the flexor muscles. The subjects threw the medicine ball forward with both hands, from a fixed distance with both arms above their head and their feet lined up. The shot was repeated 3 times and the best result was recorded in $\mathrm{cm}$ (Kamar, 2008).

Standing long jump test: Subjects jumped forward with both legs without stepping on the start line and the measurements were taken at the heel of each athlete's leg behind. Each subject repeated the jump 3 times and the best value was recorded as the measurement (Ratamess, 2012).

Data analysis: At the beginning of the study, the level of significance for the whole procedure was determined as $\mathrm{p}<0.05$ and the statistical procedures were performed using the program SPSS 23.0 for Windows. The data obtained in the pre and post tests were evaluated with the statistical package program and the significance level was determined as $\mathrm{p}<0.05$. The Shapiro-Wilk test was used to determine the distribution of the parameters used in the study. The One-Way Anova test was used to analyze the differences between the groups, and The PairedSamples t-test was used for statistical analysis of the differences within the groups.

\section{Findings}

Table-1. Descriptive statistics of KRP, KRC and KNL groups.

\begin{tabular}{c|c|c|c|c}
\hline \multirow{2}{*}{ Parameters } & KRP & KRC & KNL & \multirow{2}{*}{ A } \\
\cline { 2 - 4 } & Avg \pm Sd & Avg \pm Sd & Avg \pm Sd & p \\
\hline Age $($ years $)$ & $12,06 \pm 0,83$ & $12,1 \pm 0,79$ & $12,2 \pm 0,86$ & 0,80 \\
\hline Height $(\mathrm{cm})$ & $168,7 \pm 4,33$ & $165,7 \pm 4,39$ & $167,9 \pm 7,63$ & 0,61 \\
\hline Weight $(\mathrm{kg})$ & $55,6 \pm 6,2$ & $50,7 \pm 3,74$ & $56,5 \pm 8,03$ & 0,32 \\
\hline BMI $\left(\mathrm{kg} / \mathrm{m}^{2}\right)$ & $19,5 \pm 1,85$ & $18,2 \pm 1,15$ & $19,9 \pm 1,72$ & 0,01 \\
\hline p $<0,5$ BMI: Body mass index
\end{tabular}

$\mathrm{p}<0,5$ BMI: Body mass index.

In Table 1, as a result of the statistical analysis, it was concluded that there was a significant difference only in the BMI values of the participants in terms of demographic data and there was no significant difference between the other traits $(\mathrm{p}>0.05)$.

Table-2. The One-Way Anova test results: Preliminary test for biomotor traits between KRP, KRC and KNL groups.

\begin{tabular}{c|c|c|c|c}
\hline \multirow{2}{*}{ Parameters } & KRP & KRC & KNL & \multirow{2}{*}{$\mathbf{p}$} \\
\cline { 2 - 5 } & Avg. \pm Sd & Avg \pm Sd & Avg \pm Sd & 0,06 \\
\hline T-test $(\mathrm{sec})$ & $10,5 \pm 0,39$ & $10,3 \pm 0,32$ & $10,6 \pm 0,45$ & 0,18 \\
\hline Throw-in $(\mathrm{cm})$ & $665,3 \pm 97,2$ & $647 \pm 96,3$ & $725,6 \pm 104,2$ & 0,29 \\
\hline Flamingo $(\mathrm{sec})$ & $6,7 \pm 1,1$ & $6,2 \pm 0,8$ & $6,2 \pm 0,9$ & 0,12 \\
\hline Horizontal jump $(\mathrm{cm})$ & $164,0 \pm 17,1$ & $176,0 \pm 14,3$ & $172,2 \pm 12,8$ & 0 \\
\hline
\end{tabular}

In Table 2, there was no statistically significant difference between the KRP, KRC and KNL groups in any of the pretest values $(\mathrm{p}>0,05)$.

Table-3. The averages of differences in biomotor traits related to physical fitness of the KRP group, standard deviation values, percentages of variation and paired t-test values.

\begin{tabular}{c|c|c|c|c}
\hline Parameters & $\mathbf{N}$ & $\mathbf{A v g} \pm \mathbf{S d}$ & $\mathbf{\%}$ & $\mathbf{p}$ \\
\hline T-test $(\mathrm{sec})$ & 15 & $0,13 \pm 0,24$ & 1,00 & 0,04 \\
\hline Throw-in $(\mathrm{cm})$ & 15 & $25,3 \pm 26,9$ & 3,8 & 0,03 \\
\hline Flamingo $(\mathrm{sec})$ & 15 & $1,8 \pm 1,3$ & 26,9 & 0,00 \\
\hline Horizontal jump (cm) & 15 & $4,0 \pm 5,75$ & 2,9 & 0,01 \\
\hline ** $<0,01 *{ }^{*}<0,05:$ T-test, throw-in, flamingo, horizontal jut
\end{tabular}

**p $<0,01 ;$ * $\mathrm{p}<0,05:$ T-test, throw-in, flamingo, horizontal jump.

In Table 3, according to the paired t-test results, there was a statistically significant difference in the pre- and post-test values of the t-test, throw-in and horizontal jump tests of the KRP group $(p<0.05)$. There was a statistically significant difference in pre- and post-test values of the Flamingo test $(p<0,01)$.

Table-4. The averages of differences in biomotor traits related to physical fitness of the KRC group, standard deviation values, variation percentages and the paired t-test values.

\begin{tabular}{c|c|c|c|c}
\hline Parameters & $\mathbf{N}$ & $\mathbf{A v g} \pm \mathbf{S d}$ & $\mathbf{\%}$ & $\mathbf{p}$ \\
\hline T-test (sec) & 15 & $0,15 \pm 0,24$ & 1,9 & 0,04 \\
\hline Throw-in (cm) & 15 & $56,2 \pm 60,3$ & 8,9 & 0,003 \\
\hline Flamingo (sec) & 15 & $1,6 \pm 1,6$ & 25,8 & 0,002 \\
\hline Horizontal jump (cm) & 15 & $6,7 \pm 10,4$ & 3,9 & 0,02 \\
\hline
\end{tabular}

** $\mathrm{p}<0,01 ;{ }^{*} \mathrm{p}<0,05:$ T-test, throw-in, flamingo, horizontal jump.

Table-5. Averages of differences of biomotor traits related to physical fitness of KNL group, standard deviation values, percentages of variation and paired t-test values.

\begin{tabular}{|c|c|c|c|c|}
\hline Parameters & $\mathbf{N}$ & $\operatorname{Avg} \pm$ Sd & $\%$ & p \\
\hline T-test (sec) & 15 & $0,02 \pm 0,39$ & 0,2 & 0,80 \\
\hline Throw-in $(\mathrm{cm})$ & 15 & $8,5 \pm 12,6$ & 1,2 & 0,02 \\
\hline Flamingo (sec) & 15 & $0,6 \pm 1,3$ & 11 & 0,08 \\
\hline
\end{tabular}


In Table 4, when the pre and post tests of the KRC group were evaluated, a significant difference was found in t-test and horizontal jump tests $(\mathrm{p}<0.05)$, and a significant difference was found in throw-in and flamingo tests $(\mathrm{p}<0.01)$.

In Table 5, when the pre and post tests of the control group KNL were evaluated, a significant difference was found only in the throw-in test $(\mathrm{p}<0.05)$. No significant difference was found in other biomotor traits $(\mathrm{p}>0,05)$.

Table-6. The biomotor traits between the KRP, KRC and KNL groups and the last one-way anova test results.

\begin{tabular}{c|c|c|c|c}
\hline \multirow{2}{*}{ Parameters } & KRP & KRC & KNL & \\
\cline { 2 - 4 } Table-6. The biomotor traits between the KRP, KRC and KNL groups and the last one-way anova test results. \\
\hline T-test (sec) & $\mathbf{A v g} \pm \mathbf{S d}$ & $\mathbf{A v g} \pm \mathbf{S d}$ & $\mathbf{A v g} \pm \mathbf{S d}$ & $\mathbf{p}$ \\
\hline Throw-in (cm) & $10,4 \pm 0,51$ & $10,1 \pm 0,32$ & $10,6 \pm 0,37$ & 0,01 \\
\hline Flamingo (sec) & $690,6 \pm 96,1$ & $703,2 \pm 106,7$ & $734,2 \pm 106,2$ & 0,55 \\
\hline Horizontal jump (cm) & $4,9 \pm 1,7$ & $4,6 \pm 1,6$ & $5,5 \pm 1,6$ & 0,27 \\
\hline *p<0,05: T-test. & $168,8 \pm 17,4$ & $182,8 \pm 17,2$ & $173,7 \pm 12,3$ & 0,06 \\
\hline
\end{tabular}

In Table 6, in the post-test values of the KRP, KRC and KNL groups, only the t-test results showed that the KRC group was significantly more developed than the KNL group $(\mathrm{p}<0.05)$. There was no significant difference between the groups in terms of other biomotor traits in post-test values $(p>0,05)$.

Table-7. Correlation table of the development rates between parameters.

\begin{tabular}{c|c|c|c|c}
\multicolumn{5}{c}{ Table-7. Correlation table of the development rates between parameters. } \\
\hline Parameters & Throw-in & Flamingo & T-test & Horizontal jump \\
\hline Throw-ins & 1 & $-0,171$ & 0,051 & $-0,011$ \\
\hline Flamingo & & 1 & 0,101 & 0,182 \\
\hline T-test & & & 1 & 0,101 \\
\hline Horizontal jump & & & & 1 \\
\hline $\mathrm{n}=45,{ }^{*} \mathrm{p}<0,05$. &
\end{tabular}

When Table 7 is examined, the difference between pre-tests and post-tests, i.e. developmental values, does not show a significant relationship when looking at the relationship between each other. No relationship was found between the developing and non-developing dimensions according to the analysis.

\section{Results}

The aim of this study was to investigate the effects of two different strength training models on balance, agility and strength traits as well as the differences of volleyball players. In volleyball, motoric traits such as strength, quickness, agility, balance directly affect performance. In order to have an effective performance during the game, it is necessary to make proper training programming in accordance with the development of these traits which are the requirements of volleyball.

Volleyball is a sport where high jumps, falls and movements involving sudden changes of direction are quite present. Having the body at the most balanced position during the execution of these movements is very important for the achievement of these skills. In this context, it is known that balance skill, which forms the basis of performance and which is at the center of conditional abilities, plays an important role in successful performance of many technical skills and in maintaining certain positions of the body (Agostini et al., 2013; Erdoğan et al., 2017; Sarto et al., 2019). With core training, the body control and balance are improved, strength of many large and small muscle groups is increased, the risk of injury is reduced and efficiency in or between movements is increased due to increased balance (McGill, 2006; Willardson, 2007). This study is in parallel with the presented study. In another study, the improvement in balance performance was not significant after a nine-week core training program applied to volleyball players (Sharma et al., 2012). This study differs from our study, as core training is used as the single training method. In the present study, it was found that plyometric and quick force studies combined with core applications both had an effect on balance.

The relationship between force and speed plays an important role in the performance of volleyball. Agility development can be achieved by plyometric and strength training applications. Agility performance shows the greatest change between the ages of 12-13 and with the plateau reached, is known to develop less until the age of 15-16 (Vescovi et al., 2011). This was taken into account in the age preference of the working groups.

Research shows that plyometric and strength training practices are linked to agility development (Bozdoğan and Kızılet, 2017; Can et al., 2017; Furqoni and Sudijandoko, 2019). In another study, Pamuk and Ozkaya (2017) concluded that resistant plyometric training was effective in the development of agility. Schultz et al. (2015) concluded that there is an important relationship between strength and agility. There are studies with different opinions that are not similar to the studies that show parallelism in the correlations with the literature results related to the presented study. Bozdoğan and Kızılet (2017) examined the effect of coordination and plyometric studies on agility, jump and endurance traits and found no significant difference in agility traits in the plyometric training group.

Volleyball is a sport in which the vertical and horizontal jumps are very frequent. Volleyball player's ability to jump is an important factor in the success of the team in terms of performance (Bompa and Carrera, 2003). It is necessary to have the necessary muscle strength in order to perform explosive skills or defensive movement correctly. Muscle strength required in sports branches can be achieved by plyometric and strength training (Neagu et al., 2018). Therefore, strength and plyometric trainings are used to increase the jumping skills (Harmandeep et al., 2015). Research on the subject has shown that plyometric training is effective in jumping and agility skills (Fathi et al., 2018; Voisin and Scohier, 2019). In a study conducted with volleyball players, it was reported that plyometric training significantly improved leap and agility values (Hale et al., 2019). In another study, Abade et al. (2019) concluded that horizontal and vertical strength training they implemented had a positive effect on the jump performance. In a similar study, Fathi et al. (2018) applied plyometric training to adolescent volleyball players. As a 
result of the study, it was concluded that strength development was changed positively with plyometric training. In another study examining upper and lower extremity strength, Ateş and Ateşoğlu (2007) concluded that plyometric training had a positive effect on both upper and lower extremity strength. In the presented study, the practice groups, similar to the literature, shown improvement in the horizontal jump and throw-in values. In this respect, it can be said that core, strength and plyometric trainings have positive effects on jump, balance and strength.

In the presented study, the effects of plyometric and quick strength training, when combined with the core training, on agility, strength and balance traits were investigated. Plyometric and quick strength training combined with core training improves balance, agility and strength. When applied to the adolescent athletes, the plyometric and quick strength trainings used to increase volleyball-specific performance yields higher development compared to the adult athletes. The biomotor traits of strength, agility and balance, which are important parameters of performance in volleyball, should be implemented in a planned way by taking into consideration the requirements of the game.

\section{References}

Abade, E., N. Silva, R. Ferreira, J. Baptista, B. Gonçalves, S. Osório and J. Viana, 2019. Effects of adding vertical or horizontal force-vector exercises to in-season general strength training on jumping and sprinting performance of youth football players. Journal of Strength and Conditioning Research.Available at: https://doi.org/10.1519/JSC.0000000000003221.

Agostini, V., E. Chiaramello, L. Canavese, C. Bredariol and M. Knaflitz, 2013. Postural sway in volleyball players. Human Movement Science, 32(3): 445-456.Available at: https://doi.org/10.1016/j.humov.2013.01.002.

Ateş, M. and U. Ateşoğlu, 2007. Pliometric training of 16-18 years old male football players on the upper and lower extremity strength parameters. SPORMETRE Journal of Physical Education and Sports Sciences, 5(1): 21-28.Available at: https://doi.org/10.1501/sporm_0000000123.

Barnes, J.L., B.K. Schilling, M.J. Falvo, L.W. Weiss, A.K. Creasy and A.C. Fry, 2007. Relationship of jumping and agility performance in female volleyball athletes. Journal of Strength and Conditioning Research, 21(4): 1192-1196.Available at: https://doi.org/10.1519/00124278-200711000-00036.

Bazyler, C.D., S. Mizuguchi, C.J. Sole, T.J. Suchomel, K. Sato, A.A. Kavanaugh, B.H. DeWeese and M.H. Stone, 2018. Jumping performance is preserved but not muscle thickness in collegiate volleyball players after a taper. The Journal of Strength \& Conditioning Research, 32(4): 1020-1028.Available at: https://doi.org/10.1519/jsc.0000000000001912.

Bompa, T.O. and M.C. Carrera, 2003. Peak conditioning for volleyball. Handbook of Sports Medicine and Science, Volleyball, 29.

Bozdoğan, T.K. and A. Kızılet, 2017. The effect of coordination and plyometric exercises on agility, jumping and endurance ability in badminton players. International Journal of Sport Exercise and Training Science, 3(4): 178-187.Available at: https://doi.org/10.18826/useeabd.345236.

Busko, K., J. Lewandowska, M. Lipińska, R. Michalski and A. Pastuszak, 2013. Somatotype variables related to muscle torque and power output in female volleyball players. Acta of Bioengineering and Biomechanics, 15(2): 119-126.

Can, İ., M. Ozmen and S. Bayrakdaroğlu, 2017. The relationship between agility and weight and squat jump exercise speed and power values in trained athletes. CBU Journal of Physical Education and Sports Sciences, 12(2): 136-144.

Carpes, F.P., F.B. Reinehr and C.B. Mota, 2008. Effects of a program for trunk strength and stability on pain, low back and pelvis kinematics, and body balance: Aa pilot study. Journal of Bodywork and Movement Therapies, 12(1): 22-30.Available at: https://doi.org/10.1016/j.jbmt.2007.05.001.

Erdoğan, C.S., E.R. Fatmanur, G. İpekoğlu, T. Çolakoğlu, E. Zorba and F.F. Colakoğlu, 2017. Effects of different balance exercises on static and dynamic balance performance in volleyball players. Journal of Sport and Performance Research, 8(1): 11-18.

Fathi, A., R. Hammami, J. Moran, R. Borji, S. Sahli and H. Rebai, 2018. Effect of a 16 week combined strength and plyometric training program followed by a detraining period on athletic performance in pubertal volleyball players. Journal of Strength and Conditioning Research, 33(8): 2117-2127.

Furqoni, R.S. and A. Sudijandoko, 2019. The comparison of rope jump, cone step up, and diagonal to the power and agility. SPORTIVE Journal: Journal of Learning Research, 5(1): 140-153.Available at: https://doi.org/10.29407/js_unpgri.v5i 1.12842.

Gabbett, T., B. Georgieff and N. Domrow, 2007. The use of physiological, anthropometric, and skill data to predict selection in a talentidentified junior volleyball squad. Journal of Sports Sciences, 25(12): 1337-1344.Available at: https://doi.org/10.1080/02640410601188777.

González, R.J.M., A. Arija and V. Clemente-Suarez, 2011. Seasonal changes in jump performance and body composition in women volleyball players. The Journal of Strength \& Conditioning Research, 25(6): 1492-1501.Available at: https://doi.org/10.1519/jsc.0bo13e3181da77f6.

Haghighi, A., M. Moghadasi, A. Nikseresht, A. Torkfar and M. Haghighi, 2012. Effects of plyometric versus resistance training on sprint and skill performance in young soccer players. European Journal of Experimental Biology, 2(6): 2348-2351.

Hale, D., R. Kollock, J. Pace and G. Sanders, 2019. Vertical jump and agility performance improve after an 8-week conditioning program in youth female volleyball athletes. Journal of Physical Education and Sport, 19(1): 765-771.

Harmandeep, S., K. Satinder, R. Amita and S. Anupriya, 2015. Effects of six-week plyometrics on vertical jumping ability of volleyball players. Research Journal of Physical Education Sciences, 2320: 9011.

Herrington, L. and R. Davies, 2005. The influence of pilates training on the ability to contract the transversus abdominis muscle in asymptomatic individuals. Journal of Bodywork and Movement Therapies, 9(1): 52-57.Available at: https://doi.org/10.1016/j.jbmt.2003.12.005.

Hrysomallis, C., 2011. Balance ability and athletic performance. Sports Medicine, 41(3): 221-232.Available at: https://doi.org/10.2165/11538560-000000000-00000.

Kamar, A., 2008. Ability skills and performance tests in sport. 2nd Edn., Ankara: Nobel Publications.

Makhlouf, I., A. Chaouachi, M. Chaouachi, A.B. Othman, U. Granacher and D.G. Behm, 2018. Combination of agility and plyometric training provides similar training benefits as combined balance and plyometric training in young soccer players. Frontiers in Physiology, 9: 1-15.Available at: https://doi.org/10.3389/fphys.2018.01611.

Mcgill, S., 2010. Core training: Evidence translating to better performance and injury prevention. The Journal of Strength and Conditioning Research, 32(3): 33-46.Available at: https://doi.org/10.1519/ssc.0bo13e3181df4521.

McGill, S.M., 2006. Ultimate back fitness and performance (4th Edn). Waterloo, Canada: Backfitpro Inc, 2009 . pp: 84-86.

Neagu, N., A.-C. Gliga and T. Băţagă, 2018. A new approach to the role of antagonist muscle contraction synergism in plyometric training. Palestrica of the Third Millennium Civilization \& Sport, 19(4): 245-25 1.Available at: https://doi.org/10.26659/pm3.2018.19.4.245.

Nikseresht, A., E. Taheri and E. Khoshnam, 2014. The effect of 8 weeks of plyometric and resistance training on agility, speed and explosive power in soccer players. European Journal of Experimental Biology, 4(1): 383-386.

Oliver, G.D. and R. Di Brezzo, 2009. Functional balance training in collegiate women athletes. The Journal of Strength \& Conditioning Research, 23(7): 2124-2 129.Available at: https://doi.org/10.1519/jsc.0b013e3181b3dd9e.

Pamuk, Ö.R. and Y.G. Ozkaya, 2017. The effect of resistant pliometric training on sprint and agility performance for 15-17 years old male basketball players. Journal of Sportive Performance Research, 1(1): 1-13.

Ratamess, N., 2012. 'ACSM's foundations of strength training and conditioning'. American college of sports medicine. Indianapolis Lippincott Williams \& Wilkins, 475.

Reeser, J.C. and R. Bahr, 2017. Handbook of sports medicine and science. Volleyball: John Wiley and Sons. 
Rodríguez, R.D., J. Torres-Torrelo, F. Franco-Márquez, J.M. González-Suárez and J.J. González-Badillo, 2017. Effects of light-load maximal lifting velocity weight training vs. Combined weight training and plyometrics on sprint, vertical jump and strength performance in adult soccer players. Journal of Science and Medicine in Sport, 20(7): 695-699.Available at: https://doi.org/10.1016/j.jsams.2016.11.010.

Roetert, P.E., 2001. 3D balance and core stability. High-performance sports conditioning: modern training for ultimate athletic development. Champaign (IL): Human Kinetics.

Sarto, F., D. Grigoletto, E. Baggio, A. Paoli and G. Marcolin, 2019. Do lower limb previous injuries affect balance performance? An observational study in volleyball players. Physical Therapy in Sport, 37: 49-53.Available at: https://doi.org/10.1016/j.ptsp.2019.02.009.

Schultz, F.A., P. Cavazzoni, R.V. Carnevale, C.C. Abad, R. Kobal, L.A. Pereira and I. Loturco, 2015. Speed and power predictors of change of direction ability in elite snow athletes. Journal of Human Sport and Exercise, 10(4): 847-856.Available at: https://doi.org/10.14198/jhse.2015.104.02.

Semenick, D., 1990. The t: Test. National Strength and Conditioning Association, 12(1): 36-37.

Sharma, A., S. Geovinson and J.S. Singh, 2012. Effects of a nine-week core strengthening exercise program on vertical jump performances and static balance in volleyball players with trunk instability. The Journal of Sports Medicine and Physical Fitness, 52(6): 606-615.

Sheppard, J.M., J.B. Cronin, T.J. Gabbett, M.R. McGuigan, N. Etxebarria and R.U. Newton, 2008. Relative importance of strength, power, and anthropometric measures to jump performance of elite volleyball players. The Journal of Strength \& Conditioning Research, 22(3): 758-765.Available at: https://doi.org/10.1519/jsc.0bo13e31816a8440.

Shubert, T.E., K. McCulloch, M. Hartman and C.A. Giuliani, 2010. The effect of an exercise-based balance intervention on physical and cognitive performance for older adults: A pilot study. Journal of Geriatric Physical Therapy, 33(4): 157-164.

Sipal, M.C., 1989. Eurofit physical ability tests handbook. Ankara: GSGM Department of Foreign Relations Publication. 78.

Sopa, I.S. and M. Pomohaci, 2018. Evaluation of motor developmet and skillsin minı-volleyball game (10-12 years old). Bulletin of the Transilvania University of Brasov, Series IX: Sciences of Human Kinetics, 11(1): 95-104.

Turner, A., 2011. Defining, developing and measuring agility. UK Strenght and Conditioning Association, 22: 26-28.

Vescovi, J.D., R. Rupf, T. Brown and M. Marques, 2011. Physical performance characteristics of high-level female soccer players 12-21 years of age. Scandinavian Journal of Medicine \& Science in Sports, 21(5): 670-678.Available at: https://doi.org/10.1111/j.16000838.2009.01081.x.

Voisin, M.P. and M. Scohier, 2019. Effect of an 8-week plyometric training program with raised forefoot platforms on agility and vertical jump performance. International Journal of Exercise Science, 12(6): 491-504.

Weiner, J.S. and J.A. Lourie, 1969. In human Biology: A guide to field methods, Edinburgh: Published forthe International Biological Programme by Black well Scientific, Oxford.

Willardson, J.M., 2007. Core stability training: Applications to sports conditioning programs. The Journal of Strength \& Conditioning Research, 21(3): 979-985.Available at: https://doi.org/10.1519/00124278-200708000-00054. 